\title{
More on phi-features in and out of copular sentences: A reply to Béjar \& Kahnemuyipour $2018^{1}$
}

\author{
JUTTA M. HARTMANN \\ Institut für Deutsche Sprache \\ CAROLINE HEYCOCK \\ University of Edinburgh \\ (Received 24 April 2018)
}

\section{DERIVING NP2 AGREEMENT IN COPULAR CLAUSES}

In a copular clause where there are two nominative NPs that could be agreed with, NP1 and NP2, how can it ever happen that the copula agrees with NP2 and not the (by hypothesis) closer NP1? In the account of Béjar and Kahnemuyipour (2017, 2018) (henceforth B\&K 2017, 2018) the answer is always that NP1 lacks some phi-feature that NP2 has, so that a phi-probe searching specifically for that feature will simply skip NP1 and agree with NP2. ${ }^{2}$ In our own work, we have argued that NP2 agreement in specificational copular clauses is possible when NP1 moves out of the scope of the agreement probe(s) (Hartmann \& Heycock 2016, 2017). A central point of difference between the two proposals concerns the structure and feature content of NP1, as this directly relates to how NP2 agreement can come about.

B\&K 2017 show that in Eastern Armenian, if NP1 is third person and NP2 first or second person, then - whether the copular sentence is specificational or equative - agreement will be with NP2. They make the case that this should be accounted for by taking the phi-probe in this language to be specified for [participant], a feature only present on first and second person pronouns. Clearly, languages vary as to what features of NPs interact with agreement, ${ }^{3}$ and we find convincing B\&K's 2017 demonstration that Eastern Armenian privileges [participant], and their account of how this can be modelled.

[1] This research was partly supported by a British Academy/Leverhulme Trust Small Research Grant awarded to the two authors. We gratefully acknowledge this support.

[2] We follow the practice in B\&K 2017, 2018 in referring to the nominals involved as NPs, except when discussing details of their internal structure.

[3] It has been argued, for example for Persian, that agreement interacts with animacy and definiteness (see Ortmann 2000, 2002; Ghomeshi 2003). 
The concern of our paper (Hartmann \& Heycock 2018, henceforth H\&H 2018) was rather with the account given in B\&K 2017 for the patterns observed in specificational copular sentences in languages that do not privilege [participant] in this way. That is, in Persian, as in German, Icelandic (for some speakers) and a number of other languages, agreement either can or must be with NP2 in the specificational copular configurations in (1), while agreement in nonspecificational copular clauses like (2) is always with NP1 (BE in these examples indicates that, depending on the language, the copula can either be $3 \mathrm{sg}$ or $2 \mathrm{sg} / 2 \mathrm{pl}$ in (1a), and 3 sg or $3 \mathrm{pl}$ in (1b)).

(1) (a) The winner BE you.

(b) The source of the rumour BE the neighbours.

(2) In his dreams, the murderer is you.

Given the assumptions of B\&K 2017/2018, in order for a phi probe to skip NP1 but to find NP2, it must be the case that the latter has some feature that NP1 (the subject of the specificational sentence) lacks. This has to be the case even when NP2 has no [participant] feature, as for example in (1b). They posit that this feature is [d]. This feature is initially described in B\&K 2017 as a 'deictic' feature (hence the ' $\mathrm{d}$ '), but in fact it is not restricted to classic deictic NPs. In B\&K 2018, it is stated that it is common to 'all referential noun phrases'; from its position in the feature hierarchy that they sketch, it seems in fact to correspond to [person] (and indeed in B\&K 2017, once the feature is introduced, they refer to it as a person feature).

In a specificational sentence, then, NP2 is assumed always to have a [d] feature, while (by hypothesis) the subject, NP1, never does. In B\&K 2017, it was argued that in specificational sentences, NP1 lacks all phi-features except the minimal specification [n]. They posited the free relative-like structure in (3) for specificational subjects, and argued that the $\mathrm{D}$ head in such cases carries only [n], and that 'a full complement of phi-features would not be valued by phi-features lower in the structure [...] as they are contained inside a CP' (B\&K 2017: p. 490).

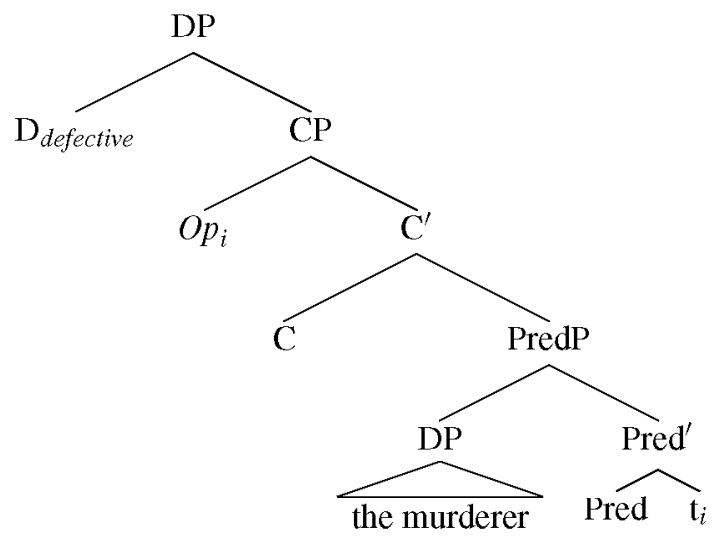


One of the main points that we made in H\&H 2018 was that this last claim could not be correct, at least for the Germanic languages that we have been working on, as all of the evidence points to specificational subjects not being entirely devoid of phi-features. In particular, whenever a language allows for NP1 agreement in specificational sentences, we find full number agreement with NP1, never just 'default' agreement (it should be borne in mind that given the semantics of specificational copular clauses, NP1 can only ever be third person). ${ }^{4}$ This is one reason why we have argued that the Germanic languages that allow NP2 agreement in specificational sentences do so because they allow NP1 to evade agreement by virtue of its structural position(s) (Hartmann \& Heycock 2016, 2017).

In their response, B\&K 2018 amend their proposal concerning the defective nature of the phi-bundle on NP1 in specificational sentences, to capture the observation that these NPs do have number features. They add to their original analysis an account of how their proposed structure for specificational subjects in (3) allows number (but crucially only number) features to be passed from the embedded audible nominal to the D head, arguing that this allows their analysis to handle the facts from Germanic - in H\&H 2018, principally Icelandic and English - that we discuss. They also make more explicit how the particular type of phisensitivity that they appeal to for these copular constructions allows a phi-probe that is specified to search for person ([d]) to also become valued for number.

Despite these amendments and clarifications, however, we believe that this proposal still does not, as it stands, provide an account of the phenomena that we have documented in Germanic. We will make two main points below. First, even given the additional assumptions that $\mathrm{B} \& \mathrm{~K}$ introduce concerning agreement for number within their structure for specificational subjects in (3), this structure still makes the wrong predictions about agreement. Second, B\&K assume a parasitic feature valuation mechanism that would undermine a number of existing accounts of 'Low Nominative' agreement in Icelandic, including, but not limited to, that found in copular constructions. We address these two issues in turn.

\section{THE STRUCTURE AND FEATURE SET-UP OF NP1}

Our first point concerns the structure in (3) and the additional mechanisms that B\&K 2018 appeal to in order to maintain their claim that specificational subjects lack the [d] feature carried by other noun phrases, while explaining the fact that in languages that allow NP1 agreement in specificational sentences, such specificational subjects trigger number agreement:

[4] A large part of our discussion in H\&H 2018 was devoted to copular clauses in Icelandic, where NP1 is a plurale tantum nominal (semantically singular but formally plural), in order to show more clearly that NP2 agreement cannot be reduced to a system where agreement is simply with the most 'marked' value for number. As these cases are not discussed in B\&K 2018, we will not discuss them further here but refer interested readers to H\&H 2018. 
(4) (a) The most likely source of the rumour is/*are Adam's parents.

(b) The most likely culprit is/*are Belinda.

(c) The most likely culprits *is/are Carl and Dana.

B\&K 2018 draw on the account of agreement in binominal small clauses (and in the predicational copular clauses that are based on them) argued for in Béjar, Denniss, Kahnemuyipour \& Yokoyama (forthcoming). They distinguish the relevant mechanism from Agree, calling it 'Merge Concord'. The details of this mechanism are not important here; the crucial point is that it is designed to ensure that a predicate nominal like a violinist/violinists has to have the same value for number as the subject:

(5) (a) I would not consider Mary \{a violinist $/ *$ violinists $\}$

(b) Mary is $\{$ a violinist $/ *$ violinists $\}$.

(c) Mary and Jane are $\left\{{ }^{*}\right.$ a violinist/violinists $\}$.

Crucially for the account of the phi-features of specificational subjects under the proposed analysis in (3), the null operator in the covert free relative is merged in the predicate position of a small clause whose subject is the audible nominal. Hence, it is 'take[n] for granted that the same number matching process applies between the subject and the operator' (B\&K 2018: 631) - that is, the null operator behaves like a violinist/violinists. Subsequently, the number value transmitted to the operator becomes accessible to the D domain when the operator fronts. In cases like (4a) and (4b), the number value will be singular, but in examples like (4c), it will be plural, by virtue of Merge Concord with the plural NP the most likely culprits:

(6) $\left[{ }_{D P} \mathrm{D}_{[\#]}\left[C P \mathrm{OP}_{[\#]}\left[C^{\prime}\left[\ldots[S C \text { the most likely culprit(s) })_{[\#]} \mathrm{t}_{\left.O P_{[\sharp]}\right]}\right]\right]\right]\right]$

As we showed in H\&H 2018, for Icelandic speakers who show the same NP1 pattern of agreement in specificational clauses as English speakers, specificational subjects where the audible nominal is a plurale tantum nominal such as upptökin ('cause(s)') also trigger plural agreement on the copula. Given the account of B\&K 2018, this means that their formal plural number must also induce a plural value on the operator:

(7) Pau spurðu hvort eldsupptökin væru ekki purrkurinn. they asked whether fire.causes be.SBJ.3PL not drought.DEF 'They asked whether the cause of the fire wasn't the drought.'

$\left[D P \mathrm{D}_{[\# P L]}\left[C P \mathrm{OP}_{[\# P L]}\left[C^{\prime}\left[\ldots\left[_{S C}\right.\right.\right.\right.\right.$ fire.causes $\left.\left.\left.\left.s_{[\# P L]} \mathrm{t}_{\left.O P_{[\# P L]}\right]}\right]\right]\right]\right]$

$\mathrm{B} \& \mathrm{~K}$ argue that the type of agreement observed in small clauses/predicative copular constructions, captured by their process of Merge Concord, has exactly the properties needed to explain the nature of specificational subjects: in particular, while nominal predicates may agree in number, they never agree in person. 
However, if we look a little more closely, we see that this proposal is problematic from three perspectives.

First, as B\&K themselves state, the proposed structure in (3) is plausibly a type of (covert) free relative. However, if we consider overt free relative clauses, we see that an operator originating in a predicate position does not acquire plural features. ${ }^{5}$

(9) A: All your aunts are \{violinists/*a violinist $\}$, aren't they?

So I guess your sisters must also be \{violinists/*a violinist $\}$, right?

B: Wrong again.

[What ${ }_{i}$ my sisters are $t_{i}$ ] is/*are not [what ${ }_{j}$ my aunts are $t_{j}$ ].

In B's answer, the matrix verb - the copula - has to be singular. If the operator in the subject free relative (what $t_{i}$ my sisters are $t_{i}$ ) was forced/able to carry plural features because of its origin in a position where it is in concord with my sisters (as proposed in B\&K 2018 for the silent operator in their structures), it should induce plural, not singular, agreement.

One might possibly argue that $w$ hat in free relatives is specified for singular, and therefore blocks concord, and that the null operator posited by B\&K 2018 might be different in this respect. However, the assumption of a valued number feature for what and an unvalued one for its silent counterpart is not only a stipulation, it also leads to the wrong results elsewhere. We consider another set of examples, one that does not rely on the analogy to overt free relatives. ${ }^{6}$ English plurale tantum nominals like jeans or spectacles behave like singulars in not forcing plural concord in copular clauses parallel to the ones cited in B\&K 2018: ${ }^{7}$

(10) (a) I only have one pair of jeans. Those jeans are a very expensive item of clothing / my favourite garment

(b) I have a couple of dresses. Those dresses are $\{*$ a very expensive item of clothing / *my favourite garment

Although it is not obvious how the Merge Concord system in Bejar et al. (forthcoming) could capture the pattern in (10a), ${ }^{8}$ for the sake of the argument, let us just assume that a solution can be found. However this is achieved, the

[5] For the copular agreement experts: note that B's response is not a specificational pseudocleft (which might have some other special properties) but an 'ordinary' equative sentence - apart from the interpretation, we can tell this because specificational pseudoclefts do not allow modification such as negation (Higgins 1979: p. 321).

[6] We take our examples from English largely because, in this language, NP1 agreement in specificational clauses is essentially obligatory; this makes the argument more straightforward than when we are considering a language like Icelandic where NP1 and NP2 agreement both occur in the modern language, as we have documented in Hartmann \& Heycock $(2016,2017)$.

[7] Of course, plural predicates are also fine with jeans, but this forces the irrelevant reading where jeans is taken to refer to multiple pairs.

[8] In Béjar et al. (forthcoming), whether or not Merge Concord applies depends on the predicative noun phrase. Here, however, the relevant factor is the nature of NP1 (the subject noun phrase). 
crucial point here is that B\&K's proposal - that the null operator in a specificational subject has the same number properties as a predicate nominal like an item of clothing - predicts that a specificational subject built around such a plurale tantum nominal should equally require singular agreement. However, this is the wrong result: the agreement is plural. ${ }^{9}$

(11) (a) $\left[D P \mathrm{D}_{[\# S G]}\left[C P \mathrm{OP}_{[\# S G]}\left[C^{\prime}\left[\ldots\left[s C\right.\right.\right.\right.\right.$ my favourite jeans $\left.\left.\left.\left.\mathrm{t}_{\left.O P_{[\# S G]}\right]}\right]\right]\right]\right]$

(b) My favourite jeans $\{$ are/*is $\}$ that pair over there.

The third problem of the structure proposed for specificational subjects is a more general one relating not only to agreement. Because, in B\&K's structure for a specificational subject, the audible NP is the subject of a small clause, there is a serious problem of overgeneration. Most specifically, nothing seems to rule out the subject of such a small clause being a first or second person pronoun, as in a free relative like the examples in (12):

(12) (a) I am [what you $_{j}$ are $\left.\left[s C \mathbf{t}_{j} \mathrm{t}_{i}\right]\right]$ (a vioinist).

(b) $\left[\right.$ What $_{i}$ you $_{j}$ are $\left.\left[s C \mathbf{t}_{j} \mathbf{t}_{i}\right]\right]$ should be important to you.

That is, the structure proposed for specificational subjects wrongly predicts that examples like (13) should be grammatical, on a par with (14):

(13) (a) *You is Ezra.

(b) $\left[D P \mathrm{D}_{[\#]}\left[C P\right.\right.$ OP $[\#]\left[C^{\prime}\left[\ldots\left[s C\right.\right.\right.$ you $\left.\left.\left.\left.[\#] \mathrm{t}_{O P_{[\#]}}\right]\right]\right]\right]$ is Ezra.

(14) (a) The murderer is Ezra.

(b) ${ }_{D D P} \mathrm{D}_{[\#]}\left[C P\right.$ OP $[H]\left[C^{\prime}\left[\ldots\left[s C\right.\right.\right.$ the murderer $\left.\left.\left.\left.[\#] \mathbf{t}_{\left.O P_{[H]}\right]}\right]\right]\right]\right]$ is Ezra.

This last problem (and in fact to some extent also the issues with agreement) could be avoided if one were to adopt instead the analysis in den Dikken (2006). In that proposal, the audible nominal in the initial 'covert free relative' is not the subject of a small clause, but its predicate, as sketched in (15), a simplified version of den Dikken's structure (p. 95):

$\left[\varnothing\left[C P \mathrm{OP}_{i}\left[C^{\prime}\left[\ldots\left[s C \mathbf{t}_{i}\right.\right.\right.\right.\right.$ [the murderer $\left.\left.\left.\left.]\right]\right]\right]\right]$ is Ezra.

However, this proposal is very problematic for a different reason. Namely, there is no non-stipulative way that we can think of that would predict that this predicate has to be a DP, rather than, say, an AP:

(16) $*\left[\varnothing\left[C P \mathrm{OP}_{i}\left[C^{\prime}\left[\ldots\left[s c \mathrm{t}_{i}\right.\right.\right.\right.\right.$ [intelligent $\left.\left.\left.\left.]\right]\right]\right]\right]$ is Ezra.

[9] It should be noted that the plural agreement in (11b) cannot be argued to be forced by the features of NP2 that pair over there. First, English requires NP1 agreement in specificational sentences. Second, that pair (of jeans) does not force plural agreement even in subject position: that pair (of jeans) is/are nice. 
In summary, we agree wholeheartedly that the syntactic structure of specificational subjects is a topic ripe for exploration. However, for English at least, that exploration has to start from the observation that the category restrictions and the agreement properties of specificational subjects exactly track the category restrictions and agreement properties of the audible NPs around which the specificational subjects are 'built'. The proposed structure seems to us to be a hindrance rather than a help in capturing this observation.

\section{THE NATURE OF PHI-AGREEMENT}

The discussion in the previous section related to the proposals in B\&K 2017/2018 about how to derive the relative phi-defectivity of NP1. The other essential components of the agreement system are of course the nature of the probe and the mechanism of agreement and valuation.

As discussed in H\&H 2018, some speakers of Icelandic have an NP2 agreement pattern. For B\&K's proposal to work for Icelandic NP2 agreement, the probe must be searching specifically for $[\mathrm{d}]$, which - as expected in the kind of featuregeometry they assume, given that [d] is essentially equivalent to [person] dominates 'participant' and 'speaker', but crucially not number, see (17), taken from B\&K 2018:

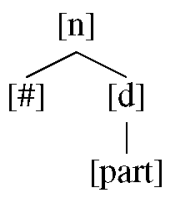

In order for the valuation process to yield the right results, B\&K 2018 make explicit their assumption that if the phi-probe is searching for [d], or [participant], once it makes a match, even the non-dominated number feature on the probe will be valued 'parasitically'. This is a necessary move, given that in the more elaborated system in B\&K 2018, NP1 has an accessible number feature. If number probed separately from person ([d]), the prediction would be that, in specificational sentences in Persian and Icelandic (for speakers with NP2 agreement), we would find person agreement with NP2 but number agreement with NP1, which is not the case.

It should be noticed, however, that the assumption that a probe can search for a particular feature but have non-dominated features valued 'parasitically' is not an innocent one. In particular, there is by now an extensive literature on agreement, much of it drawing on Béjar (2003) and Béjar \& Rezac (2003), that relies on the possibility of person and number - or other phi-features - probing separately. Crucially, in such proposals, probing by person results in valuation only of the subpart of the feature structure dominated by person, and the same for number. This aspect of how agreement works in a feature-geometric approach to phi-features is set out very explicitly in Preminger (2014: Chapter 4), where it is 
presented as a synopsis of ideas from Béjar \& Rezac (2003); Preminger goes to some lengths to distinguish between this property of agreement and the 'featural coarseness' of clitic-doubling, which 'copies feature-sets in their entirety' (p. 31).

It could be that there are distinct types of phi-sensitivity in probes, with one type allowing for the kind of 'parasitic' valuation of phi-features that Preminger takes to be the hallmark of clitic-doubling rather than agreement, and another type restricting valuation to the substructures matching the specification of the probe. As analysed in B\&K 2018, Persian and Eastern Armenian would instantiate the first type. In addition to whatever concerns one might have about this theoretical multiplication, however, there is a specific problem that arises from the attempt to extend the same analysis to Icelandic. Again, we have shown in Hartmann \& Heycock $(2016,2017,2018)$ that some Icelandic speakers allow/prefer NP2 agreement in specificational clauses; the claim in B\&K 2018 is that this can be dealt with by assuming a [d] probe, plus parasitic evaluation of number. However, Icelandic is a language where there are long-standing arguments that person and number agreement have to be treated as separate probes (whether or not these probes are distinct heads), see, in particular, Béjar \& Rezac (2003), Sigurðssson (2004), Sigurðsson \& Holmberg (2008) and Preminger (2014).

Most of these arguments relate to agreement with 'Low Nominatives' in Dative-Nominative constructions. Beyond the Dative-Nominative cases, in Hartmann \& Heycock $(2016,2017)$, we showed that Icelandic has three agreement options in specificational copular clauses: NP1 agreement, NP2 agreement and number-only agreement with NP2; see (18).

(18) Hann var að̃ velta fyrir sér hvort ...

he was wondering if

(a) aðalvandamálið væri pið.

main problem.DEF be.3sg you.PL

'the main problem is you.pl.'

(b) aðalvandamálið varuð pið.

main problem. DEF be.2PL you.PL

'the main problem is you.pl.'

(c) aðalvandamálið varu pið.

main problem.DEF be.3PL you.PL 'the main problem is you.PL.'

(Hartmann \& Heycock 2017: 268f)

We have argued that this third pattern of number-only agreement is the result of number and person being two independent probes. In our configurational analysis, the pattern is straightforwardly accounted for: as NP1 can move above number, but below person, NP1 may intervene for the person probe, without doing so for number. We do not see how this pattern could be handled given the assumptions about agreement made in B\&K 2018. 
It should be noted that, as alluded to briefly above, it is not possible simply to graft the possibility of separate number and person probes onto the account for NP2 agreement given in B\&K 2017/2018. In such a system, the person probe would search for [d], and find and agree for person with NP2. The number probe, however, would find and agree for number with NP1 (given the amendment in B\&K 2018 to take into account the fact that NP1 has number features). That is, it would predict not the attested 'number-only' NP2 agreement but an unattested 'person-only' NP2 agreement, and would also block the attested full (person and number) agreement with NP2. Therefore, we think that an approach along the lines of B\&K 2017/2018 does not account for the patterns of agreement in Icelandic that we have described and analysed. There is a configurational aspect needed in the structure. NP1 in a specificational sentence has phi-features that are in principle accessible to a probe, but it can be invisible to the probe when outside its domain.

\section{CONCLUSion}

In this reply, we have argued that the adjustments made in B\&K 2018 in response to H\&H 2018 are not sufficient to account for the range of data we encounter in Icelandic. First, we argued against the specific proposal of number inheritance for specificational subjects. The structure and mechanism proposed in B\&K 2018, drawing on Béjar et al. (forthcoming), does not make the correct predictions for number agreement, if we consider either overt free relatives or specificational sentences involving plurale tantum nouns in English. Second, we have argued that the probe structure and agreement mechanism proposed for Persian specificational copular clauses in B\&K 2017 and extended to Icelandic in B\&K 2018 is inconsistent with the wider picture of agreement in Icelandic, some of which we have discussed elsewhere (Hartmann \& Heycock 2016, 2017). In Icelandic, there is a range of evidence that number and person need to be separate probes, evidence that is incompatible with B\&K's 2018 proposal of 'parasitic' agreement in number. While we are convinced by arguments in B\&K 2017 that the phi-sensitivity of probes can vary cross-linguistically, the featural specification of the probe proposed, in combination with a featurally defective NP1, does not suffice to capture the facts in Icelandic, contra the suggestion in B\&K 2018 that the system outlined there can provide a unified account that includes the Icelandic and English data. We thus still do not see a viable alternative to taking into consideration the configurational position of NP1, as we have proposed.

\section{REFERENCES}

Béjar, Susana. 2003. Phi-syntax: A theory of agreement. Ph.D. dissertation, University of Toronto.

Béjar, Susana, Jessica Denniss, Arsalan Kahnemuyipour \& Tomohiro Yokoyama. forthcoming. Number matching in binominal small clauses. In María J. Arche, Antonio Fábregas \& Rafael Marin (eds.), The grammar of copulas across languages (Oxford Studies in Theoretical Linguistics), Oxford University Press. 
Béjar, Susana \& Arsalan Kahnemuyipour. 2017. Non-canonical agreement in copular sentences. Journal of Linguistics 53.3, 463-499.

Béjar, Susana \& Arsalan Kahnemuyipour. 2018. Not all phi-features are created equal: A reply to Hartmann \& Heycock 2018. Journal of Linguistics 54.3, 629-635. [This issue]

Béjar, Susana \& Milan Rezac. 2003. Person licensing and the derivation of PCC effects. In Ana Teresa Perez-Leroux \& Yves Roberge (eds.), Romance linguistics: Theory and acquisition, 49-62. Amsterdam: John Benjamins.

den Dikken, Marcel. 2006. Relators and linkers: The syntax of predication, predicate inversion and copulas. Cambridge, MA: MIT Press.

Ghomeshi, Jila. 2003. Plural marking, indefiniteness, and the noun phrase. Studia Linguistica 57.2, 47-74; doi:10.1111/1467-9582.00099.

Hartmann, Jutta M. \& Caroline Heycock. 2016. Evading agreement: A new perspective on low nominative agreement in Icelandic. In Christopher Hammerly \& Brandon Prickett (eds.), The 46th Annual Meeting of the North East Linguistic Society (NELS), vol. 2, 67-80. Amherst, MA: GLSA.

Hartmann, Jutta M. \& Caroline Heycock. 2017. Variation in copular agreement in Insular Scandinavian. In Höskuldur Thráinsson, Caroline Heycock, Hjalmar P. Petersen \& Zakaris Svabo Hansen (eds.), Syntactic variation in insular Scandinavian, 233-275. Amsterdam: John Benjamins.

Hartmann, Jutta M. \& Caroline Heycock. 2018. A remark on Béjar \& Kahnemuyipour 2017: Specificational subjects do have phi-features, Journal of Linguistics 54.3, 611-627. [This issue]

Higgins, Roger. 1979. The pseudo-cleft construction in English. New York: Garland.

Ortmann, Albert, 2000. Where plural refuses to agree: Feature unification and morphological economy. Acta Linguistica Hungarica 47, 249-288.

Ortmann, Albert. 2002. Economy-based splits, constraints, and lexical representations. In Ingrid Kaufmann \& Barbara Stiebels (eds.), More than words (Studia Grammatica), 147-177. Berlin: Akademie Verlag.

Preminger, Omer. 2014. Agreement and its failures (Linguistic Inquiry Monographs 68), Cambridge, MA: MIT Press.

Sigurðsson, Halldór Ármann. 2004. The syntax of Person, Tense, and speech features. Italian Journal of Linguistics/Rivista di Linguistica 16, 219-251.

Sigurðsson, Halldór Ármann \& Anders Holmberg. 2008. Icelandic dative intervention: Person and number are separate probes. In Roberta D’Alessandro, Susann Fischer \& Gunnar Hrafn Hrafnbjargarson (eds.), Agreement restrictions, 251-279. Berlin: Mouton de Gruyter.

\author{
Authors' addresses: (Hartmann) \\ Institut für Deutsche Sprache, Augustaanlage 32, \\ D-68165, Mannheim, Germany \\ hartmann@ids-mannheim.de \\ (Heycock) \\ University of Edinburgh, PPLS, 3 Charles Street, \\ Edinburgh EH8 9AD, Scotland, UK \\ caroline.heycock@ed.ac.uk
}

